\title{
NREL Reveals Links Among Climate Control, Battery Life, and Electric Vehicle Range
}

Researchers at the National Renewable Energy Laboratory (NREL) are providing new insights into the relationships between the climate-control systems of plug-in electric vehicles and the distances these vehicles can travel on a single charge. In particular, NREL research has determined that "preconditioning" a vehicleachieving a comfortable cabin temperature and preheating or precooling the battery while the vehicle is still plugged in-can extend its driving range and improve battery life over the long term.

One of the most significant barriers to widespread deployment of electric vehicles is range anxiety-a driver's uncertainty about the vehicle's ability to reach a destination before fully depleting the battery's charge. NREL researchers are studying the effects of climate-control loads on range and exploring how to maintain cabin comfort through climate-control strategies that mitigate the impacts on range.

The battery pack in an all-electric vehicle (EV) or a plug-in hybrid electric vehicle (PHEV) supports not only the vehicle's propulsion system, but also auxiliary systems like heating and air conditioning. These climate-control loads can reduce the electric ranges of EVs and PHEVs and increase fuel consumption in PHEVs. The loads are more substantial when the climate-control systems are used to initially bring the cabin to a comfortable temperature during very hot or cold weather at the outset of a trip. Thermal preconditioning reduces these initial loads on the battery by drawing power from the grid or another off-board electric power source. To gain a better understanding of this approach, a team of NREL researchers has quantified the potential benefit of thermal preconditioning to electric range and battery life.

"It is remarkable how much impact climate-control loads have on electric range," says NREL engineer Laurie Ramroth. "We found that these loads can reduce range by more than a third, and that cabin thermal preconditioning can increase range by up to 19\%."

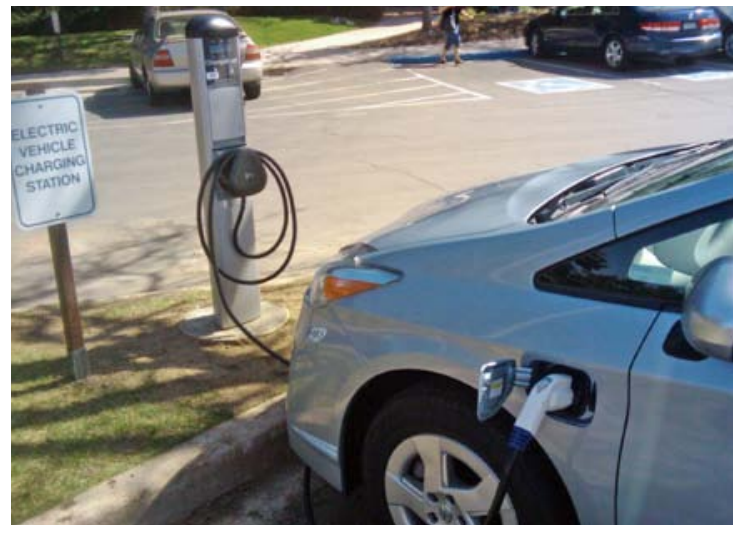

The heating and air-conditioning systems in an electric vehicle are powered by the battery. In very hot or cold temperatures, such climate-control loads can significantly reduce the vehicle's all-electric range. However, the impact on electric range can be mitigated if the initial cool-down or warm-up can take place while the vehicle is charging. Photo by Mike Simpson, NREL/PIX 18870
The Spectrum of Clean Energy Innovation

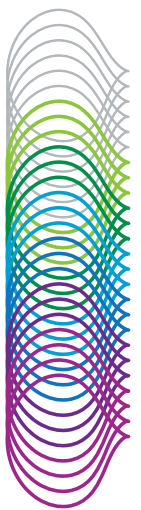

Fundamental Science

Market-Relevant Research

Systems Integration

Testing and Validation

Commercialization

Deployment

Through deep technical expertise and an unmatched breadth of capabilities, NREL leads an integrated approach across the spectrum of renewable energy innovation. From scientific discovery to accelerating market deployment, NREL works in partnership with private industry to drive the transformation of our nation's energy systems.

This case study illustrates NREL's innovations in Systems Integration through Deployment.
NREL is a national laboratory of the U.S. Department of Energy, Office of Energy Efficiency and Renewable Energy, operated by the Alliance for Sustainable Energy, LLC. 


\section{EV100 Performance}

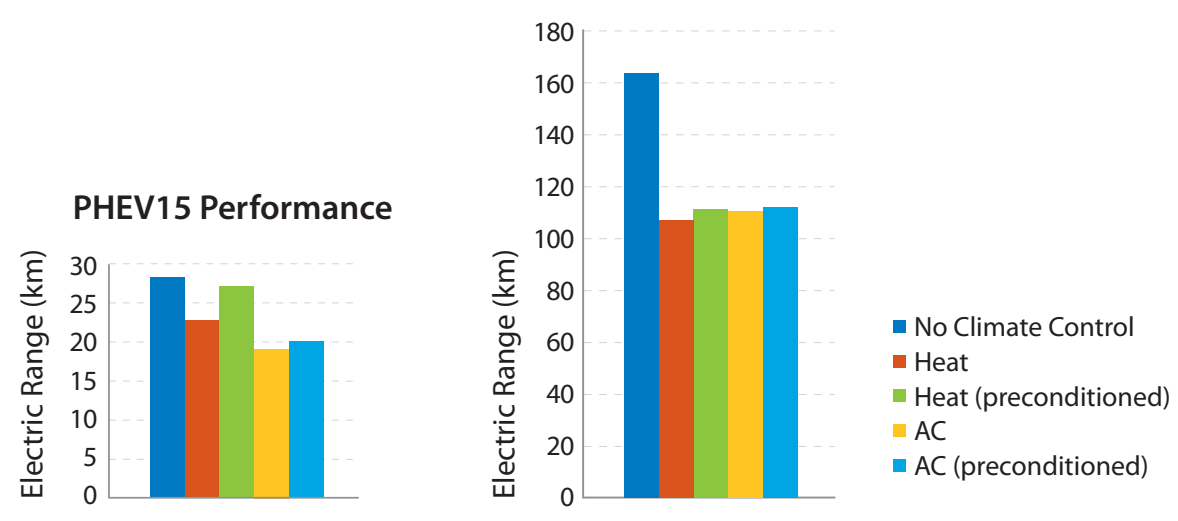

NREL researchers found that preconditioning an EV or PHEV can restore several kilometers of range. Simulations of a PHEV with a 15-mile electric range (PHEV15) and an EV with a 100-mile range (EV100) found the greatest improvement when pre-heating a PHEV15. Illustration by Stacy Buchanan, NREL

NREL researchers undertook the analysis by modeling three electric vehicle platforms: a PHEV with a 15-mile all-electric range (PHEV15), a PHEV with a 40-mile all-electric range (PHEV40), and an EV with a 100-mile range (EV100). Next, the team developed heating and air-conditioning load profiles for cold and hot weather scenarios. The researchers then simulated vehicle performance with and without thermal preconditioning for each scenario, using the driving patterns that the U.S. Environmental Protection Agency employs to simulate city and highway driving.

The analysis showed that climate-control system loads can increase fuel consumption in PHEVs by as much as 61\% and can decrease electric range by up to $35 \%$ in EVs. The range benefits of thermal preconditioning were most pronounced in the PHEV15 platform, in which preconditioning with heat in the cold-temperature scenario yielded a 19\% increase in range, compared to no thermal preconditioning. Across the other platforms and temperature scenarios, preconditioning resulted in range increases between $1 \%$ and $6 \%$.

"The restoration of several kilometers of range may resonate with consumers for whom range anxiety is a potential barrier to purchasing an electric vehicle," Ramroth says.

NREL also characterized battery wear in hot and cold scenarios with and without thermal preconditioning, using a computer model of lithium-ion battery life. Battery aging is caused by a number of factors, including elevated temperatures. But precooling the battery before driving represents a partial solution. The researchers found that battery-capacity loss over time is driven by ambient temperatures rather than by climate-control loads, but that pre-cooling the battery can reduce capacity loss by $7 \%$.

"When a vehicle sits outside on a hot summer day, the battery is at least as warm as the outside air, and it gets even hotter while the car is being driven," says Ramroth. "This reduces battery life, and batteries aren't cheap. This study found that preconditioning the battery offers some protection against capacity loss."

NREL's findings reveal the extent to which preconditioning can provide drivers with tangible range benefits and prolong battery life. The analysis also sheds light on potential future directions for electric-vehicle research and development.

"Our results show that efficiency improvements in heating and air-conditioning systems could substantially extend electric range," Ramroth says.

\section{NREL Tool Helps Assess Grid Readiness for Electric Vehicles}

NREL is helping utilities determine whether electricity distribution infrastructure is ready to handle the demands of plug-in vehicles.

Combining a wealth of vehicle performance statistics with load data from partner utilities, including the Hawaiian Electric Company and Xcel Energy, NREL analyzed the impacts of vehicle charging on distribution transformers. After running millions of simulations replicating varying climates and conditions, NREL is now able to predict aging rates for transformers as EVs are added to existing loads.

"In the majority of scenarios, we've found that transformers have enough excess capacity to charge electric vehicles," says NREL researcher Michael Kuss. "Only in extreme cases does vehicle charging have a negative long-term impact. Even when you take preconditioning into account, we foresee that existing grid infrastructure is ready for the electrification of transportation."

The NREL tool allows users to input vehicle trip and weather data; transformer load profiles and ratings; electric vehicle penetration, charging rates, and battery sizes; utility rates; the number of houses on each transformer; and public charging availability. The tool then identifies vulnerabilities in the system and predicts the annual aging rate of the transformers. Once the analysis has been conducted for a particular area or utility, the results can help determine whether more detailed evaluation is necessary, and whether transformer replacements are required.

"Organizations like college campuses and military bases that operate their own small grids have really appreciated this analysis," says Kuss. "We can evaluate their readiness quickly and easily so that they don't have to hire someone to conduct an extensive study."

The model has also proven useful in demonstrating synergies between EVs and distributed sources of renewable energy. Small-scale renewables, like solar panels on a rooftop, can both provide clean energy for vehicles and reduce demand on distribution infrastructure by supplying loads at the point of consumption.

\section{National Renewable Energy Laboratory}

15013 Denver West Parkway

Golden, CO 80401

303-275-3000 • www.nrel.gov

NREL is a national laboratory of the U.S. Department of Energy, Office of Energy Efficiency and Renewable Energy, operated by the Alliance for Sustainable Energy, LLC.

NREL/FS-6A42-53603 • June 2012

Printed with a renewable-source ink on paper containing at least $50 \%$ wastepaper, including $10 \%$ post consumer waste.

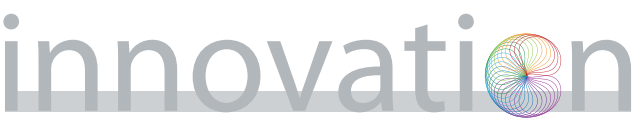

